\title{
Design of Broadband Dual-Polarized Rectenna Array for WPT Applications
}

\author{
Guan-Pu Pan, Kuan-Chih Chiu, Tsung-Lin Li, Jwo-Shiun Sun \\ Department of Electronic Engineering, National Taipei University of Technology, \\ 1, Sec. 3, Zhongxiao E. Rd., Taipei 10608 \\ TAIWAN, R.O.C.
}

Received: August 14, 2020. Revised: April 1, 2021. Accepted: April 14, 2021. Published: April 19, 2021.

\begin{abstract}
A broadband dual-polarized microstrip array antenna designed is proposed. To achieve wide $10 \mathrm{~dB}$ bandwidth for broadband operation, the technique of applying a ladder-shaped monopole antenna type with a rectangular slot insertion in the ground plane is implemented. The proposed design showed wide impedance bandwidth of the 1702-2755 $\mathrm{MHz}(47.2 \%)$. In addition, adding an open slot into the rectangular radiating element with an asymmetric ground plane was used and resulted in a slightly displacement of the radiation pattern. The $1 \times 2$ array type for two ladder-shaped patch array elements are arranged in symmetric feed network. By meticulously arrangement the two array antennas' positions to achieved good ports isolation, with $10 \mathrm{~dB}$ bandwidth for the operating bands in free-space can be achieved. This antenna is used as a rectenna (rectifying antenna), which receives the RF energy of vertical and horizontal polarization wave in free space for $2.4 \mathrm{GHz}$ wireless power transmission. The rectifier circuit setup using two zero biased rectifier and voltage doubler circuit. A matching network designed with small size chip components have a significant improvement in impedance matching and eliminate high order harmonics between the antenna and rectifying circuit. The proposed dual-polarized rectenna provided the RF-to-DC conversion efficiency as high as $78.8 \%$ when $14 \mathrm{dBm}$ microwave power was received at 2.4 GHz with a $1 \mathrm{~K} \Omega$ load.
\end{abstract}

Keywords-Dual-polarized, rectenna, wireless power transmission, voltage doubler circuit.

\section{INTRODUCTION}

E nergy harvesters take fuel from ambient sources present $\bigcup_{\text {around environment. Types of ambient sources considered }}$ and used for energy harvesting are wind, solar, vibration, temperature gradient, thermoelectric, Radio Frequency (RF). The Wireless Power Transmission (WPT) technology is able to transfer the RF power. Some research suggests rectenna to turn on and turn off the radio nodes belonging to a Wireless Sensor
Network (WSN) [1-5]. One of the most important elements in WPT is the Rectenna which is composed by a receiving antenna and rectifying circuit to covert electromagnetic energy to direct current (DC) energy.

Because of the Circular Polarization (CP) does not require the polarization alignment of the electric field at the transmitting and receiving antennas [6-8]. Unfortunately, in general the transmitting antenna is vertical or horizontal polarization wave, $\mathrm{CP}$ antenna as receive antenna then loss power due to polarization mismatch. One of solutions to overcome the issue have been proposed, the dual-polarization antenna receive vertical and horizontal energy respectively is which there is no power loss due to polarization matched [9-11]. Therefore, proposed a new design of a dual polarized array antenna. to achieve a good matching wideband frequency and isolation level that ensures a good diversity performance.

\section{BROADBAND ARRAY ANTENNA}

\section{A. The Antenna Array Element Structures}

Fig. 1 presents the geometry of the proposed ladder-shaped monopole antenna with ladder-shaped structure. They are etched on inexpensive $0.8 \mathrm{~mm}$ thick FR4 substrate with relative permittivity $\varepsilon_{\mathrm{r}}=4.4$ and loss tangent $\tan \delta=0.0245$.

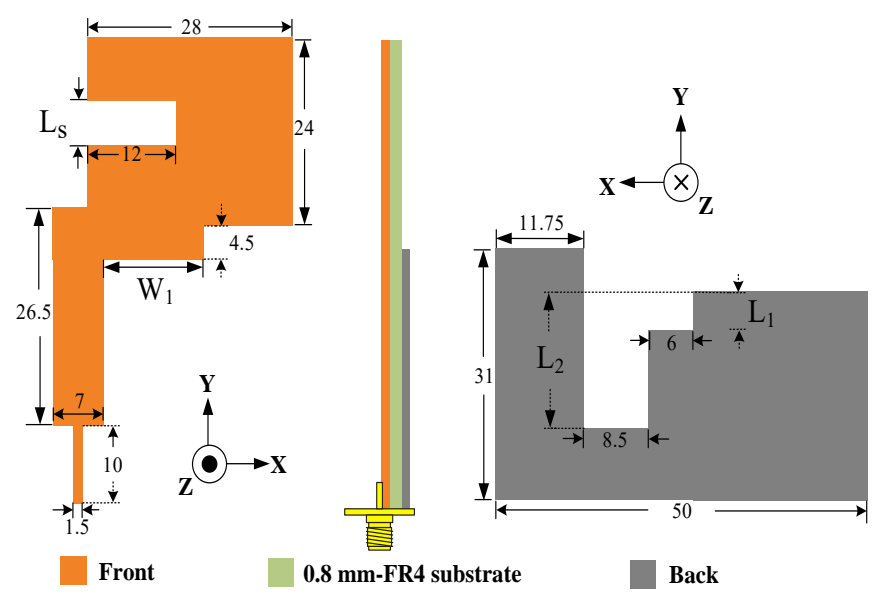


Fig. 1 Geometry of signal element broadband antenna, $\mathrm{L} 1=5, \mathrm{LS}=5$, $\mathrm{L} 2=17, \mathrm{~W} 1=13.5$ (unit: $\mathrm{mm}$ )

The main radiating structure of antenna is a ladder-shaped patch and consists of three sub-patches with sizes of $7 \mathrm{~mm} \times$ $26.5 \mathrm{~mm}, \mathrm{~W} 1 \times 4.5 \mathrm{~mm}$, and $28 \mathrm{~mm} \times 24 \mathrm{~mm}$. A $50 \Omega$ microstrip line feed with dimensions of $1.5 \mathrm{~mm} \times 10 \mathrm{~mm}$ is used to feed the patch. Embedded on the left side of the radiating element is a rectangular slot with LS $\times 12 \mathrm{~mm}$. As for the ground plane, it is printed on the bottom side of the substrate and has an overall size of $31 \mathrm{~mm} \times 50 \mathrm{~mm}$. An inverted L-shaped slot vertical section is with dimension L2 $\times 8.5 \mathrm{~mm}$, whereas the horizontal section with sizes of $\mathrm{L} 1 \times 6 \mathrm{~mm}$ is embedded behind feed-line into the ground plane. In this design, for improving the impedance matching and thus expanding good broad bandwidths [12], with a stepped slot, that is, multiple stages of an impedance transformer. In other words, the use of a multi-stage structure can generate multiple resonance modes, so that multiple similar resonance frequency points generate continuous bandwidth. Thus, this makes it possible to have a broadband impedance-matching condition.

\section{B. Experimental Results and Discussion}

Simulated and measured return loss from the two input ports are shown in Fig. 2. The impedance matching over the 1.8 and $2.4 \mathrm{GHz}$ bands is seen to all better than $10 \mathrm{~dB}$.

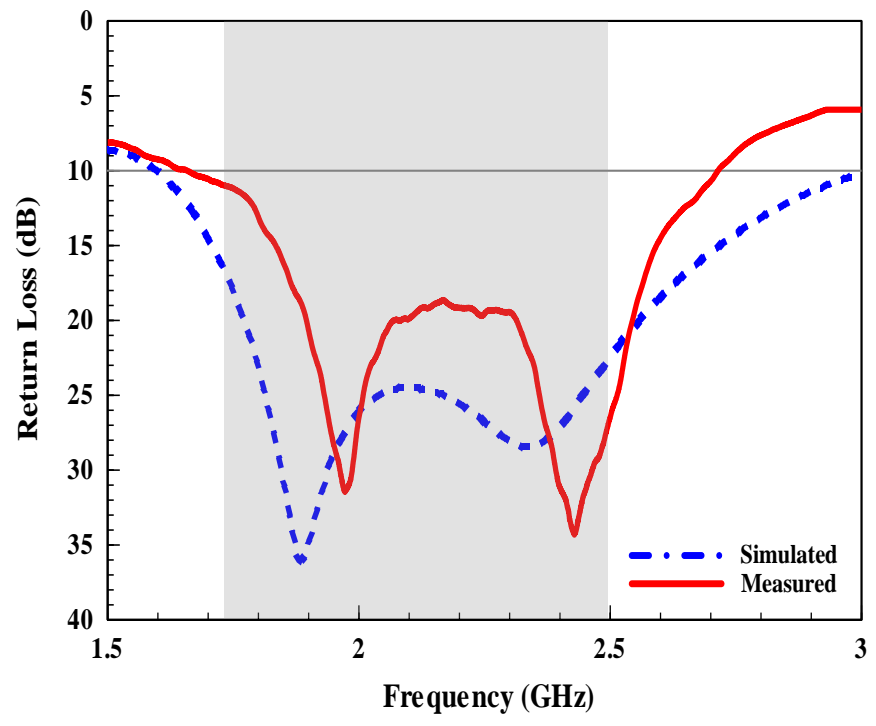

Fig. 2 Simulated and measured return loss of the proposed antenna

Fig. 3 and Fig. 4 show the measured far-field radiation patterns of the proposed antenna at $1.8 \mathrm{GHz}$ and $2.4 \mathrm{GHz}$. The normalized patterns show monopole like radiations. Notably, loading an open slot into the rectangular radiating element with an asymmetric ground plane is used and resulted in a slightly displacement of the radiation pattern tends to $-\mathrm{x}$ direction. This structure can make the radiation pattern more concentrated when designing the array antenna, and can increase the gain of the array antenna compared with a symmetrical ground structure. The peak gain of the proposed antenna, measured within the $1.8 \mathrm{GHz}$ and $2.4 \mathrm{GHz}$ operating bands are shown in Fig. 5, peak gain from 0.61 to $0.8 \mathrm{dBi}$ is measured between 1.8 $\mathrm{GHz}$ and $2.4 \mathrm{GHz}$

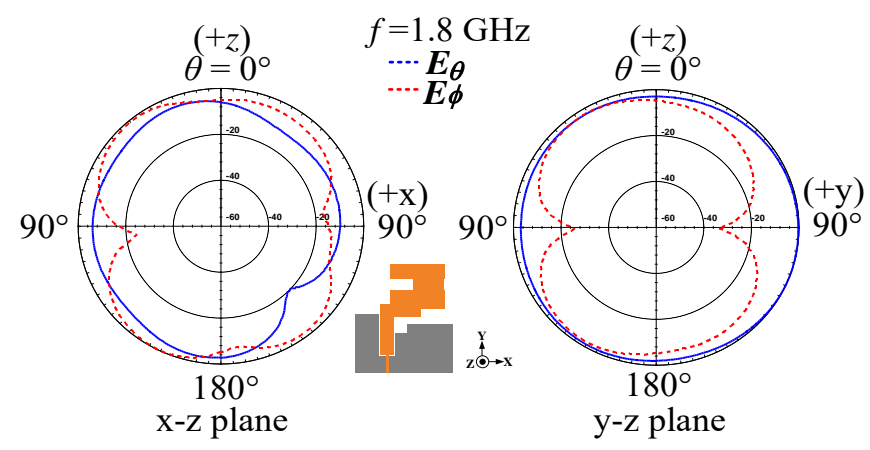

Fig. 3 Measured radiation patterns at $1.8 \mathrm{GHz}$

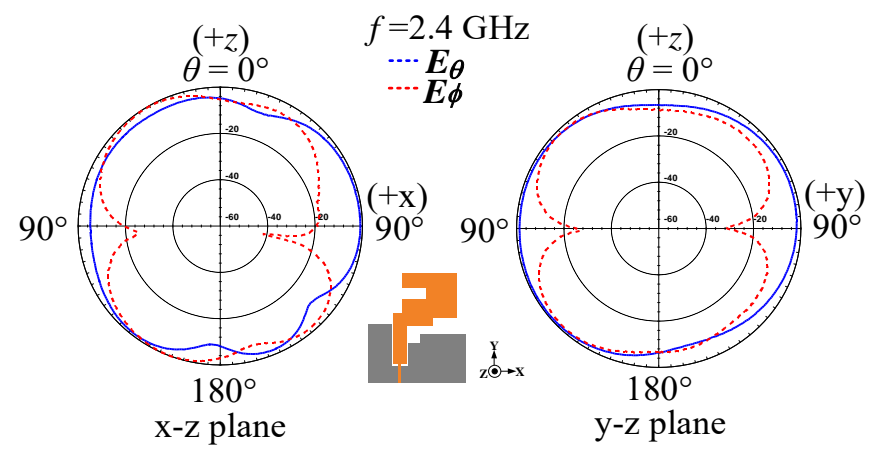

Fig. 4 Measured radiation patterns at $2.4 \mathrm{GHz}$

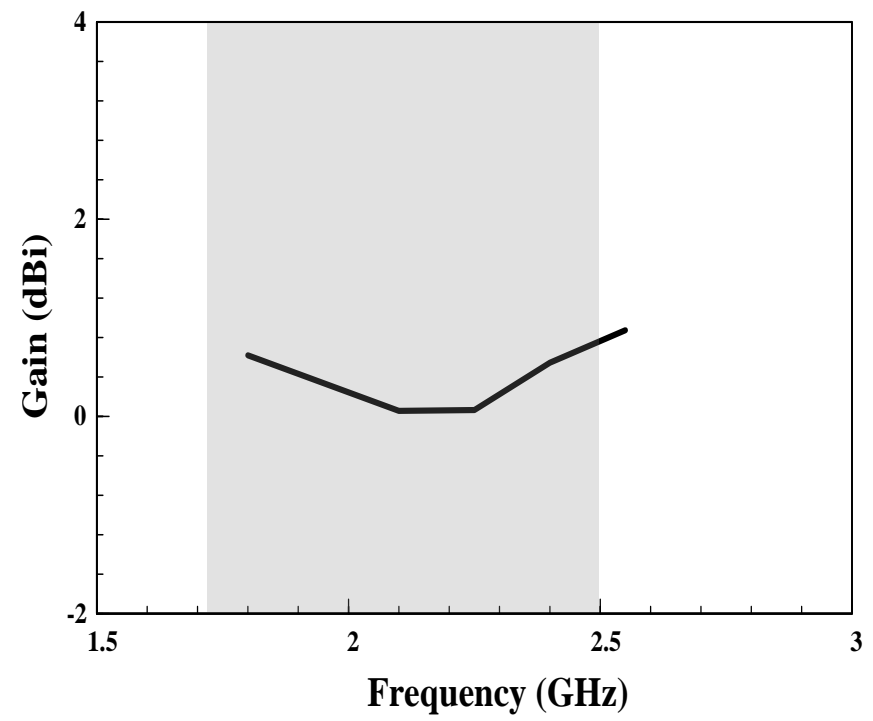

Fig. 5 Measured gain of the proposed antenna

\section{DUAL-POLARIZED RECTENNA ARRAY}

\section{A. Dual-Polarized Array Antenna}

Fig. 6. It is composed of two broadband arrays aligned orthogonally and symmetrically, dual polarization performance 
of the whole array is achieved. The two monopole radiators have been separated distance (S) of $7 \mathrm{~mm}$ between the two radiators.

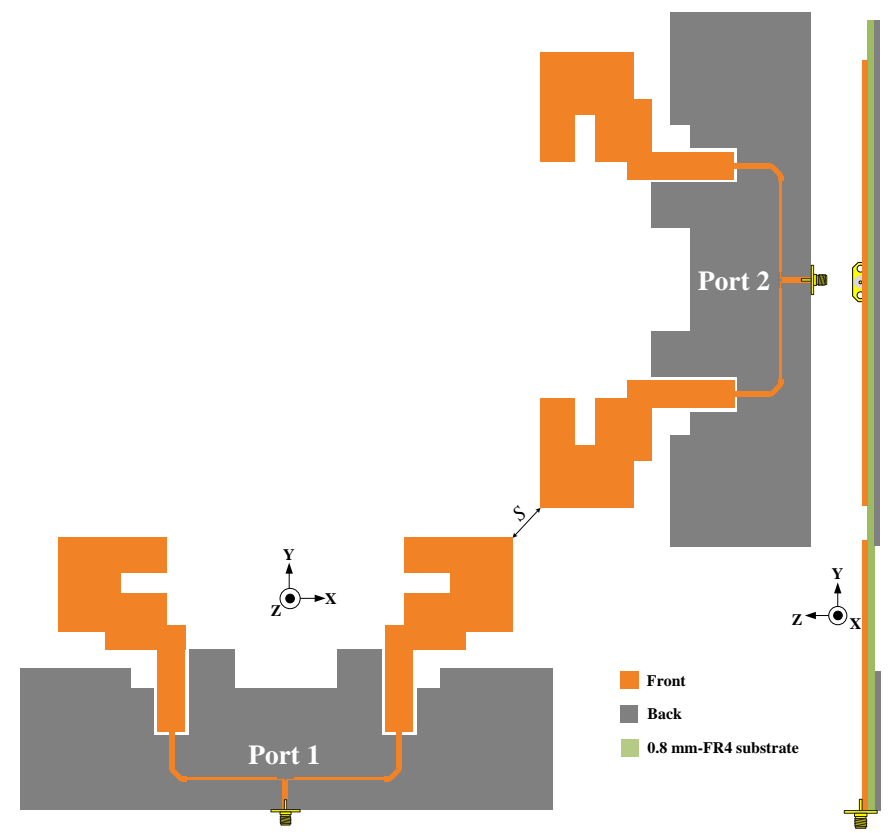

Fig. 6 Geometry of the proposed dual-polarized array antenna, $S=7$ $\mathrm{mm}$

Fig. 7. shows the feed network that is used to feed the two single element antennas, and the two feeding terminals (sharing the same output amplitude and phase) from $\mathrm{B}$ and $\mathrm{C}$ are individually connected to the microstrip line feed that has been described earlier.

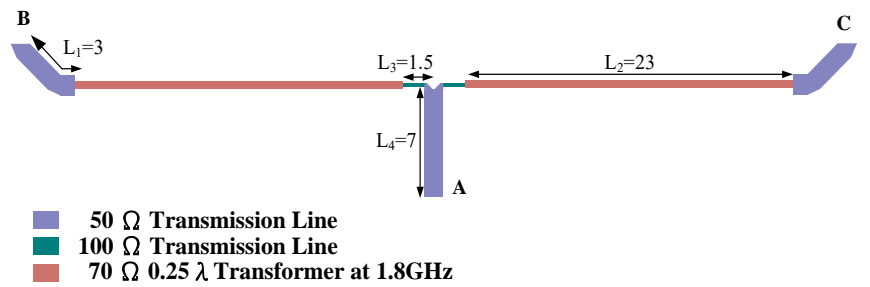

Fig. 7. Corporate feed network of proposed broadband array antenna.

In Fig. 8, one sees the improvement of the isolation across the operating band, as the $\mathrm{S}$ increases from 5 to 7 which can reduce the mutual coupling through separating the radiation patterns of the two radiators.

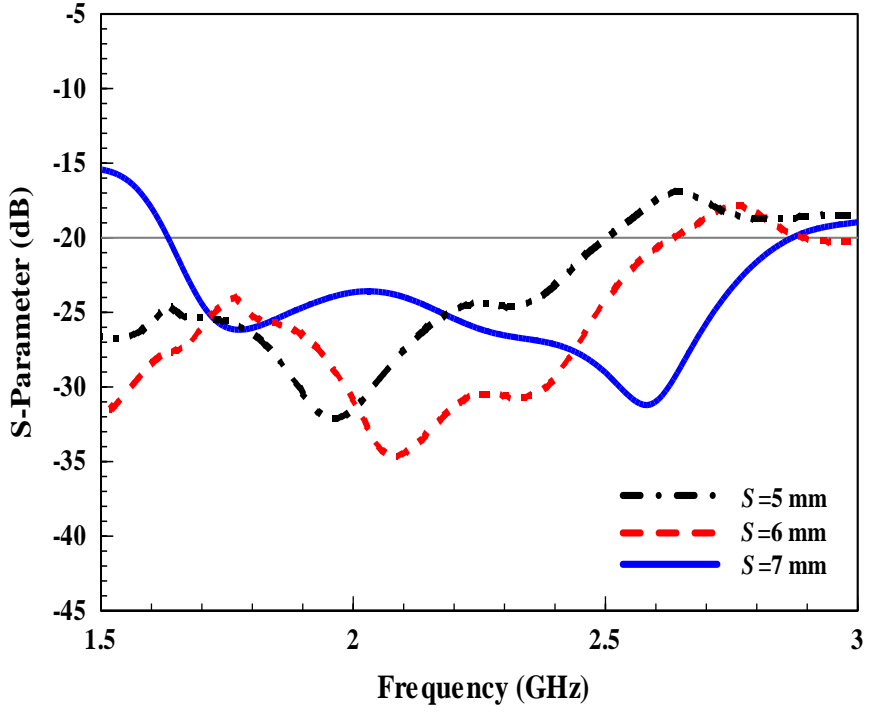

Fig. 8 Simulated S-parameters when the $\mathrm{S}$ varies

The return loss and isolation for both the simulation and measurement are shown in Fig. 9. The impedance bandwidth of the both port1 and prot2 are $53.4 \%(1555 \mathrm{MHz}-2693 \mathrm{MHz})$, and good agreement is demonstrated between the two results. Fig. 9 (b) show a measured isolation meet these specifications more than $20 \mathrm{~dB}$ in all of the band.

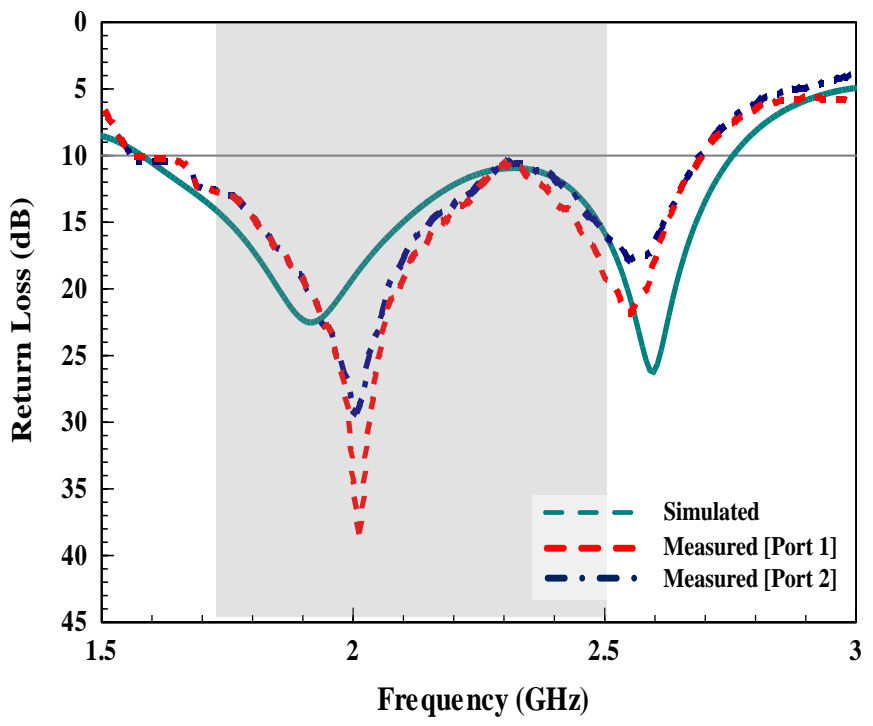

(a) 


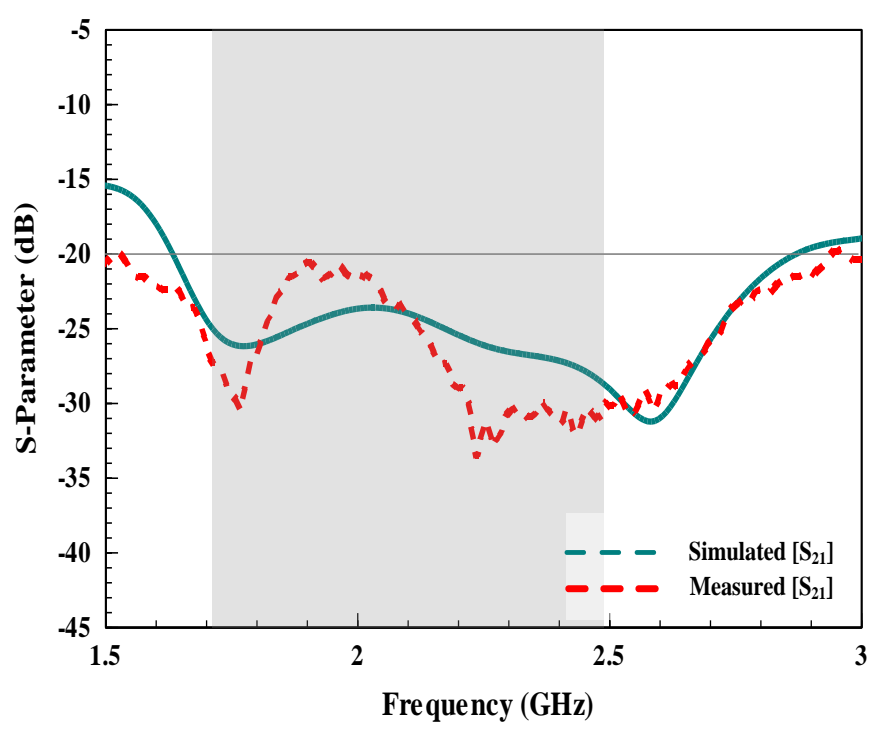

(b)

Fig. 9 Measured return loss and isolation of proposed structure: (a) return loss, (b) isolation

The measured far-field radiation patterns of the proposed antenna in the two principal planes for broad operating bands at $1.8 \mathrm{GHz}$ and $2.4 \mathrm{GHz}$ are presented in Fig. 10 and Fig. 11. In the measurement, port 2 is terminated with a $50 \Omega$ load when port1 is excited, and vice versa. Note that port 2 are not shown here because their patterns resemble port1, which is result in good isolation properties. Therefore, the beam pattern of the two antennas is spontaneously divided into two different directions. The measured gains of the proposed antenna excited from the two input ports are shown in Fig. 12. The average gains are about $3.3 \mathrm{dBi}-6.1 \mathrm{dBi}$.

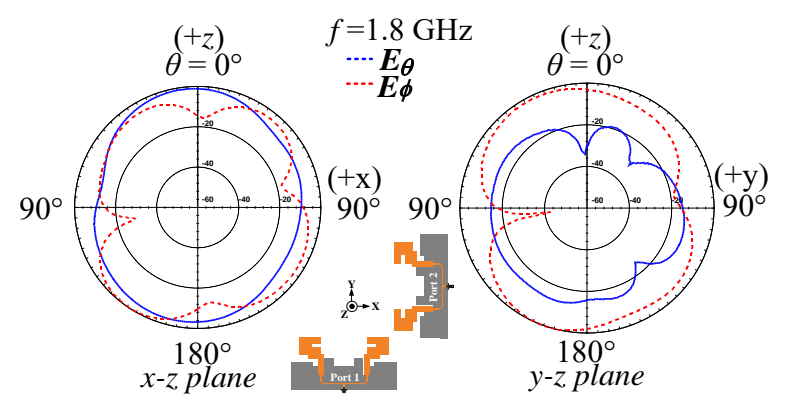

Fig. 10 Measured radiation patterns at $1.8 \mathrm{GHz}$

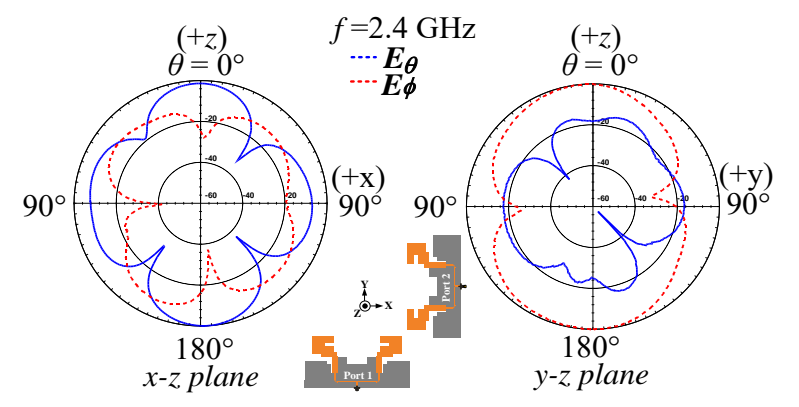

Fig. 11 Measured radiation patterns at $2.4 \mathrm{GHz}$

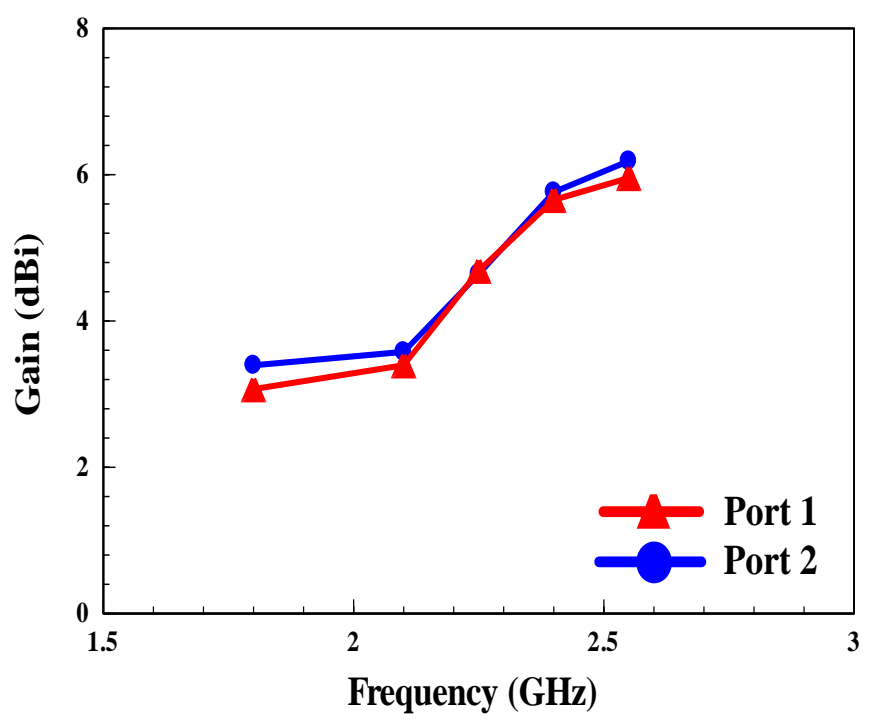

Fig. 12 Measured gain of the proposed antenna

\section{B. Rectifying Circuit Design}

The diagram of the rectifying circuit is presented in Fig. 13. The RF to DC conversion circuit is formed of HSMS-2862 zero-bias Schottky detector diode pair, a capacitor and a load resistor. The double output voltage is created by storing charge at the series capacitor $\left(\mathrm{C}_{2}\right)$ during the negative phase of $\mathrm{RF}$ signal through the shunt diode while charge in is accumulated with the input potential during the positive signal phase by turning on the series diode and flowed to DC filter capacitor $\left(\mathrm{C}_{3}\right)$. The impedance matching circuit has two chip components $\mathrm{C}_{1}=0.68 \mathrm{pF}$ and $\mathrm{L}_{1}=3.0 \mathrm{nH}$ for 50 characteristic impedance at $2.4 \mathrm{GHz}$. By the matching circuit played the role as low-pass filter, the harmonics generated by the non-linear diodes can be largely suppressed for efficiency improvement.

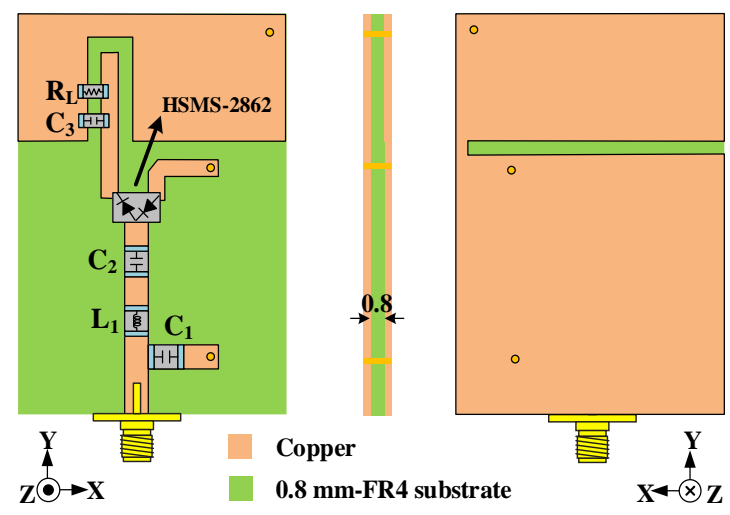

Fig. 13. Schematic and photograph of rectifier

\section{Rectenna Measurement}

The photographs of proposed rectenna array is shown in Fig. 14. The measurement setup refers to the approach in [13]. The rectenna is tested in an anechoic chamber. The transmitting 
terminal is composed of a vector signal generator connected to a broadband standard horn antenna, which is used as the source of RF power for WPT system. The receiving terminal is divided into two parts to receive the signal. First, in order to obtain the $\mathrm{RF}$ power $\left(P_{\text {receiver }}\right)$ of the rectenna, a spectrum analyzer is connected to the receiving antenna that has not yet been connected to the rectifier circuit. In the second part, the antenna structure is exactly the same, but the rectifier circuit is added to the back end to form a rectenna, and a multimeter is connected to the load resistance $\left(R_{L}\right)$ at the back end of the rectenna to measure the output DC voltage $\left(V_{D C}\right)$. The conversion efficiency $\left(\eta_{c}\right)$ is defined as

$$
\eta_{C}=\frac{V_{D C}^{2}}{R_{L}} \cdot \frac{1}{P_{\text {receiver }}}
$$
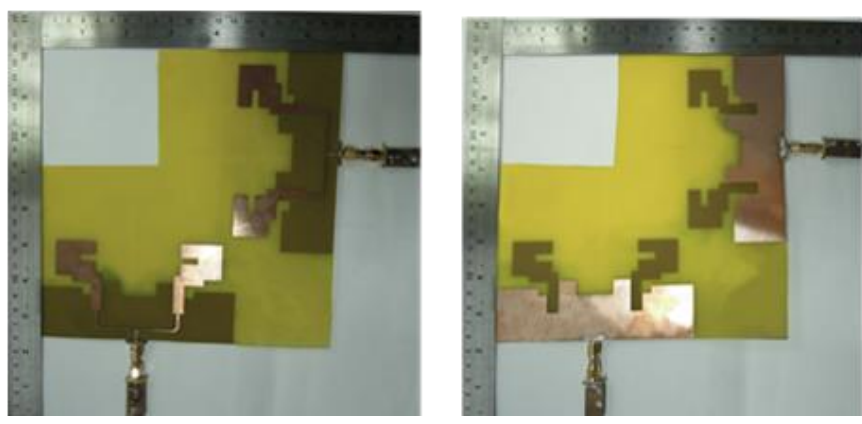

Fig. 14 the photographs of proposed rectenna

Measured voltage and the conversion efficiency are shown in Fig. 15 and Fig. 16. The RF to DC conversion efficiency is $78.8 \%$ at $30 \mathrm{dBm}$ with $1 \mathrm{~K} \Omega$ load resistance. The rectenna operating at $2.4 \mathrm{GHz}$ has dc output of the maximum output DC potential is $8.2 \mathrm{~V}$ with $5 \mathrm{~K} \Omega$ load resistance.

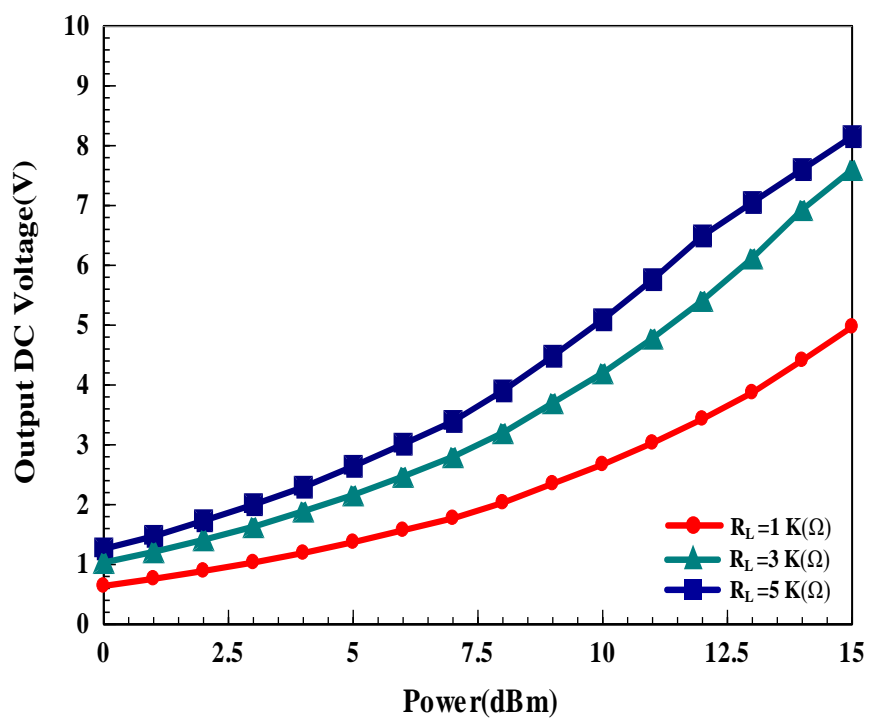

Fig. 15 Rectenna dc output voltage versus the received RF power is measured

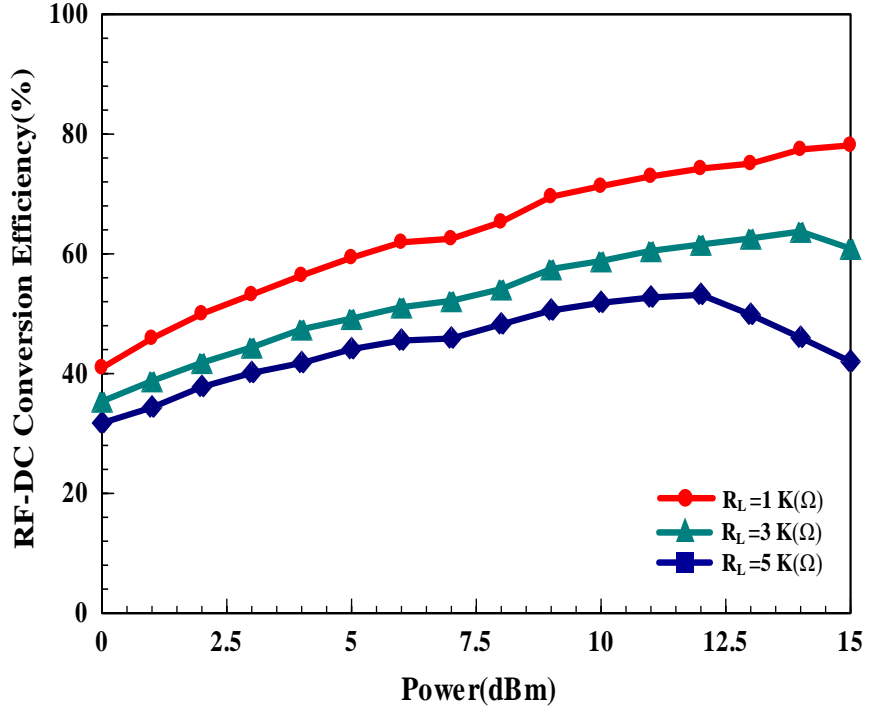

Fig. 16 Rectenna dc output voltage versus the received RF power is measured

\section{CONCLUSION}

A broadband dual-polarized array antenna is presented. As a result, the proposed antenna meets the frequency band requirement, bandwidths are $53.4 \%$ for both polarizations, and shows good isolation performance and stable radiation patterns over the entire $1.8 \mathrm{GHz}$ and $2.4 \mathrm{GHz}$ bandwidth. The dual-polarized rectenna array operated at $2.45 \mathrm{GHz}$ with measured gain about $3.3 \mathrm{dBi}-6.1 \mathrm{dBi}$. The used doubler rectifier provides optimum $78 \%$ RF-DC conversion efficiency at $15 \mathrm{dBm}$ incident power and $1 \mathrm{~K} \Omega$ load resistance.

\section{References}

[1] F. Congedo, G. Monti, L. Tarricone, and V. Bella, A 2.45-GHz Vivaldi Rectenna for the Remote Activation of an End Device Radio Node, IEEE Sensors Journal, Vol. 13, No. 9, 2013, pp. 3454-3461.

[2] Y. C. Huang, G. P. Pan, T. L. Li, and J. S. Sun, Design of dual polarized rectenna for wireless power transmission, APEMC, 2015, pp. 269-271

[3] S. T. Khang et.al., Microwave Power Transfer with Optimal Number of Rectenna Arrays for Midrange Applications, IEEE Antennas and Wireless Propag. Letters, Vol. 17, No. 1, 2018, pp. 155-159.

[4] X. Li, L. Yang, L. Huang, Novel Design of 2.45-GHz Rectenna Element and Array for Wireless Power Transmission, IEEE Access, Vol. 7, 2019, pp. 28356-28362.

[5] H. Sun, W. Geyi, A New Rectenna Using Beamwidth-Enhanced Antenna Array for RF Power Harvesting Applications, IEEE Antennas and Wireless Propag. Letters, Vol. 16, 2017, pp. 1451-1454.

[6] Yu-Jiun Ren and Kai Chang, New 5.8-GHz circularly polarized retrodirective rectenna arrays for wireless power transmission, IEEE Trans. on Microwave Theory and Techniques, Vol. 54, No. 7, 2006, pp. 2970-2976. 
[7] Y. Yang et.al., A 5.8 GHz Circularly Polarized Rectenna With Harmonic Suppression and Rectenna Array for Wireless Power Transfer, IEEE Antennas and Wireless Propag. Letters, Vol. 17, No. 7, 2018, pp. 1276-1280.

[8] Y. Liu et.al., A Low-Profile Lightweight Circularly Polarized Rectenna Array Based on Coplanar Waveguide, IEEE Antennas and Wireless Propag. Letters, Vol. 17, No. 9, 2018, pp. 1659-1663.

[9] M. Barba, "A High-Isolation, wideband and dual-linear polarization patch antenna," IEEE Trans. on Antennas and Propag., Vol. 56, No. 5, 2008, pp. 1472-1476.

[10]C. Wu, C. Lu, and W. Cao, Wideband Dual-Polarization Slot Antenna with High Isolation by Using Microstrip Line Balun Feed, IEEE Antennas and Wireless Propag. Letters, Vol. 16, 2017, pp. 1759-1762.

[11]M. Shirazi et.al., A Reconfigurable Dual-Polarization Slot-Ring Antenna Element with Wide Bandwidth for Array Applications, IEEE Trans. on Antennas and Propag., Vol. 66, No. 11, 2018, pp. 5943-5954.

[12] W. Liu and D. Huang, Multiband ladder-shaped monopole antenna for digital television and wireless communications, Microwave Opt Technol Lett, Vol. 51, 2009, pp. 2124-2127.

[13] Hucheng Sun, Yong-Xin Guo, Miao He and Zheng Zhong, Design of a High-Efficiency 2.45-GHz Rectenna for Low-Input-Power Energy Harvesting, IEEE Antennas and Wireless Propag. Letters, Vol. 11, 2012, pp. 929-932.

[14] (Journal Online Sources style) K. Author. (year, month). Title. Journal [Type of medium]. Volume(issue), paging if given. Available: http://www.(URL)

[15] R. J. Vidmar. (1992, August). On the use of atmospheric plasmas as electromagnetic reflectors. IEEE Trans. Plasma Sci. [Online]. 21(3). pp. 876-880. Available: http://www.halcyon.com/pub/journals/21ps03-vidmar

\section{Creative Commons Attribution License 4.0 (Attribution 4.0 International, CC BY 4.0)}

This article is published under the terms of the Creative Commons Attribution License 4.0

https://creativecommons.org/licenses/by/4.0/deed.en_US 